\title{
Geographic variation in richness and shell size of eastern North American land snail communities
}

\author{
Jeffrey C. Nekola \\ Biology Department, Castetter Hall, University of New Mexico \\ Albuquerque, New Mexico 87131 U.S.A.
}

\begin{abstract}
Richness and shell size distributions of land snail faunas were analyzed from 838 sites sampled within ten geographic regions spread across a $2,300 \times 2,800 \mathrm{~km}$ area in eastern North America, extending from tundra and taiga to tallgrass prairie, mixed boreal-hardwood, deciduous and evergreen subtropical forest. A total of 410,667 individuals from 166 taxa were encountered. These data documented: (1) Eastern North American land snail communities are frequently marked by high levels of syntopic species richness. Over $52 \%$ of sites exceeded 12 co-occurring taxa, with almost $10 \%$ supporting more than 24 taxa. Two percent of sites harbored 30 or more taxa. (2) Site richness was inversely related to latitude, with an almost 5-fold decrease towards the north. (3) Site richness was least in oligotrophic and grassland habitats, and greatest on base-rich bedrock outcrops. (4) Communities are dominated by taxa with maximum shell dimensions of $<5$ $\mathrm{mm}$, representing almost $75 \%$ of species and over $80 \%$ of individuals within sites in most regions. Taxa with shells $10 \mathrm{~mm}$ or larger never constituted more than $16 \%$ of taxa and $7 \%$ of individuals in average sites. (5) Northern communities harbored a more narrow range of size distributions, with both the largest $(10+\mathrm{mm})$ and smallest $(<2 \mathrm{~mm})$ size classes becoming less frequent. (6) Medium and large shelled taxa were most frequent in outcrop and lowland forest habitats, while minute species were most frequent in grasslands. (7) The contribution of $\alpha$ and $\gamma$ diversity to regional richness was greatest in the north, with $41 \%$ of taxa being found on average in Churchill, Manitoba sites. However, the contribution of $\beta$ diversity peaked in the south. These results suggest that the latitudinal gradient in land snail richness in eastern North America is related not only to an increase in the number of niches and guilds towards the south, but also to increased niche overlap towards the north
\end{abstract}

Key words: biodiversity, terrestrial gastropod, latitudinal gradients, diversity partitioning

\section{INTRODUCTION}

One of the most ubiquitous patterns in community ecology is the increase of species richness per unit area with decreasing latitude. This trend has been noted for groups as varied as trees, birds, mammals, arthropods, and planktonic foraminifera (Whittaker, 1975; Brown and Gibson, 1983), and has been related to habitat favorability and productivity, number of potential niches, niche breadth, overlap, and the rate of geographic turnover (Whittaker, 1975; Shmida and Ellner, 1984; Ricklefs, 1990; Terborgh, 1992).

Such large scale diversity patterns tend to be less well documented for invertebrates, especially those that spend much of their life in the soil. Investigation of some soil groups (e.g. bacteria, fungi, nematodes, and micro-arthropods) is further complicated because only a small fraction of their species pools have been taxonomically described (Behan-Pelletier and Newton, 1999).
Terrestrial gastropods serve as an important exception, being both taxonomically diverse and well described. Over 35,000 species are believed to exist globally (Barker, 2001), with roughly 3,600 occurring in Europe, 1,600 in Australia, 1,400 in New Zealand, and 1,200 in North America (Pilsbry, 1948; Bank et al., 1998; Barker and Mayhill, 1999). Although alpha-level taxonomy remains poorly known in places such as east Africa, Madagascar (e.g. Emberton et al., 1996, 1997), New Zealand (Barker, 2004) and eastern Australia (Stanisic and Ponder, 2004), the description of new species has slowed in western Europe and eastern North America to less than $1 \%$ of the total fauna per decade. These rates are comparable to (or less than) more conspicuous groups such as vascular plants. In addition, taxa within a single community may span $5-6$ orders of magnitude in volume (minimum $=1 \mathrm{~mm}^{3}$ ) and represent a variety of trophic levels, including polyphagous detritivores, herbivores, 
omnivores, and carnivores (Kerney and Cameron, 1979; Burch and Pearce, 1990).

Terrestrial gastropods may thus serve as an important model group for investigation of mechanisms underlying large-scale invertebrate diversity. The following study documents land snail community richness and shell-size distribution across eastern and central North America. These data will be used to determine if significant diversity patterns exist, and the possible mechanisms underlying them. Specific questions to be addressed include whether: (1) richness varies across geographic regions and habitats; (2) the size distribution of taxa and individuals varies across regions and habitats; and (3) the relative contributions of $\alpha, \beta$, and $\gamma$ diversity (sensu Cody, $1986)$ vary between regions and habitats.

\section{METHODS}

\section{Study Region}

Land snail faunas were analyzed within ten geographic regions located in a 2,300 $\times 2,800 \mathrm{~km}$ area centered on east-central North America, with a maximum extent of $3,040 \mathrm{~km}$ occurring between Georgetown, South Carolina and Cape Merry,
Churchill, Manitoba (Figure 1). The study area encompasses parts of the Interior and Northern provinces of the eastern North American molluscan division (Burch and Pearce, 1990). Two hundred and seventeen taxa are known from this area (Table 1), or approximately $40 \%$ of the eastern North American fauna (Hubricht, 1985). Dominant vegetation varies from tundra and taiga in the north to tallgrass prairie in the west to mixed borealhardwood, deciduous and evergreen subtropical forest in the east and south (Barbour and Billings, 1988).

\section{Study Sites}

A total of 838 sites (Table 1) were surveyed. The number per region varied from 215 in the western Niagara escarpment to 11 in the northern Ozarks. Five major habitat types were surveyed: rock outcrop (318 sites), upland forest (186), lowland forest (160), upland grassland (64), and lowland grassland (110). Except for the Ozarks, where sampling was limited to calcareous bedrock outcrops and upland grasslands, an attempt was made to sample representative examples of each habitat type known to exist within each region. While certain habitat types were absent from certain regions (e.g. no rock outcrops exist within

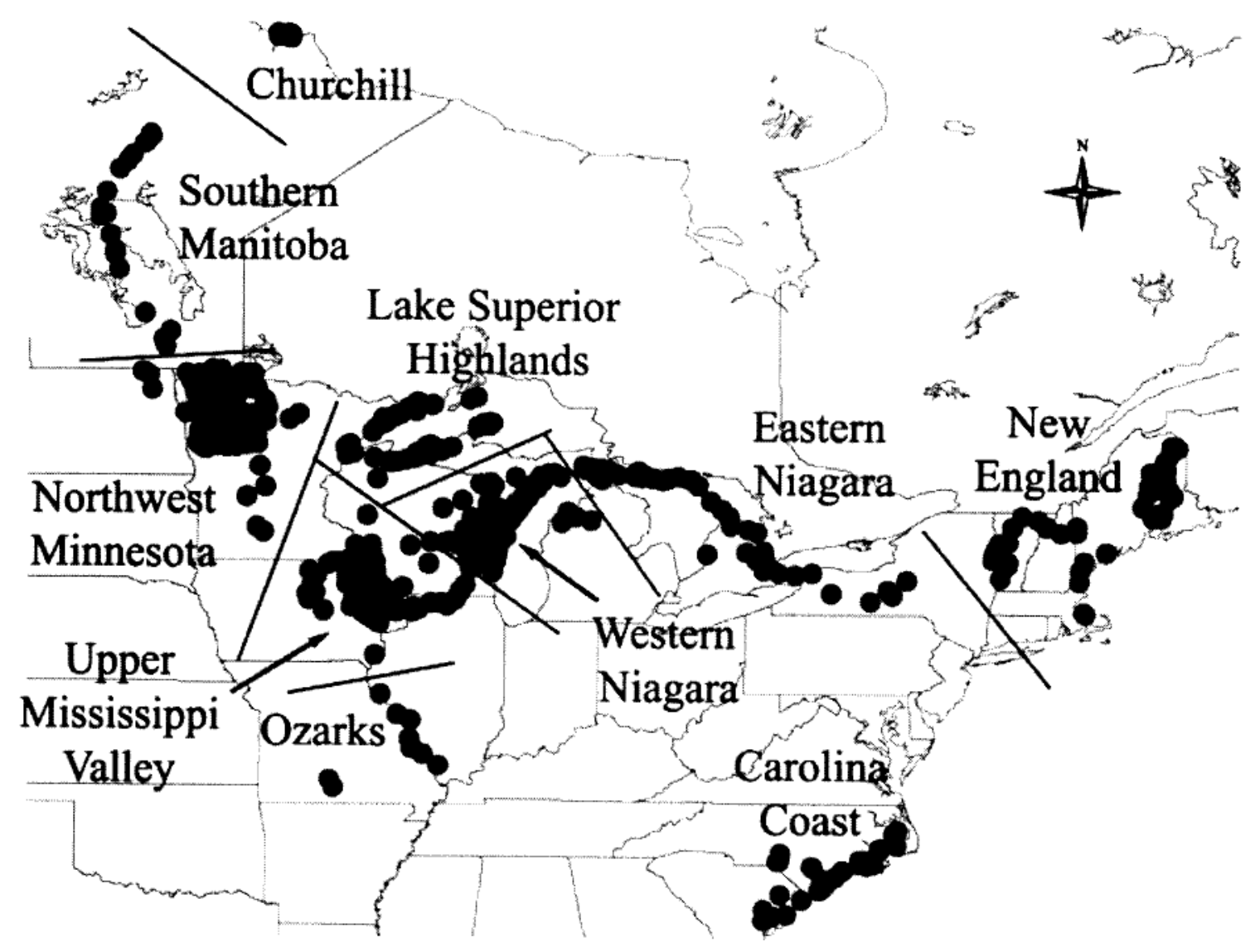

Figure 1 Map of eastern North America showing location of the ten sample regions and 838 sample sites 
Table 1 Regional dataset overview: sample sites

\begin{tabular}{lccccccc}
\hline Region & Rock & Upland & $\begin{array}{c}\text { Habitat Types } \\
\text { Outcrop } \\
\text { Fowland } \\
\text { Forest }\end{array}$ & $\begin{array}{c}\text { Fpland } \\
\text { Grassland }\end{array}$ & $\begin{array}{c}\text { Lowland } \\
\text { Grassland }\end{array}$ & Total & Oligotrophic \\
\hline Carolina Coast & 7 & 11 & 14 & 2 & 4 & 38 & $82 \%$ \\
Ozarks & 9 & 0 & 0 & 2 & 0 & 11 & $0 \%$ \\
New England & 17 & 16 & 20 & 3 & 9 & 65 & $31 \%$ \\
Upper Mississippi & 71 & 8 & 0 & 25 & 15 & 119 & $3 \%$ \\
Eastern Niagara & 38 & 7 & 14 & 1 & 9 & 69 & $6 \%$ \\
Western Niagara & 98 & 39 & 42 & 9 & 27 & 215 & $1 \%$ \\
Lake Superior highlands & 72 & 1 & 4 & 5 & 0 & 82 & $27 \%$ \\
Northwestern Minnesota & 0 & 89 & 54 & 14 & 35 & 192 & $8 \%$ \\
Southern Manitoba & 3 & 10 & 7 & 0 & 4 & 24 & $17 \%$ \\
Churchill & 0 & 3 & 2 & 7 & 11 & 23 & $9 \%$ \\
Total & 315 & 184 & 157 & 68 & 114 & 838 & $13 \%$ \\
\hline
\end{tabular}

northwestern Minnesota), a minimum of four were sampled from each. Rock outcrop habitats included carbonate, sandstone, shale, igneous, and quartzite cliffs, lakeshore carbonate ledges, and algific talus slopes. Upland forest habitats included oakhickory, maple-basswood, hemlock-birch, balsamwhite spruce, paper birch, aspen, and pine (jack, loblolly, pond, red, southern or white) forest or savanna plus rocky forests and those along lakeshores. Lowland forest habitats included black ash, tamarack, black spruce, northern and Atlantic white cedar stands plus floodplains, shrub-carr, bay forests, swamp forests, medium and tall pocosins. Upland grassland habitats included mesic, xeric, and sand prairies, bedrock glades, alvars, igneous rock shorelines, old fields, and upland tundra. Lowland grassland habitats included wet prairies, sedge meadows, fens, calcareous meadows, cobble beaches, low pocosins, acid peatlands, and low tundra. Descriptions for most of these may be found in Nekola (1999). While these habitat groupings differ from those typically used in European studies (e.g. wooded vs. open carbonate rock outcrops, lowland fens, upland flushes; Kerney and Cameron, 1979), they capture the major compositional trends present in eastern North American land snail communities (Nekola, 2003).

Although most sampled sites possessed high base-status, oligotrophic sites (granite, quartzite, rhyolite, and most shale and sandstone outcrops, pocosins, acid peatlands, sand dunes, pine forest and savanna) were sampled from all the habitat groups and regions except the Ozarks. The proportion of such habitats was greatest in coastal Carolina (82\%), New England (31\%), the Lake Superior highlands $(27 \%)$, and southern Manitoba $(17 \%)$.

\section{Field Methods}

The latitude-longitude position of each site was determined using either USGS 7.5 minute topographic maps or a hand-held GPS.
Documentation of terrestrial snail faunas (excluding slugs) from representative $100-1,000 \mathrm{~m}^{2}$ areas within sites was accomplished by hand collection of larger shells and litter sampling for smaller taxa. Soil litter sampling was primarily used as it provides the most complete assessment of site faunas (Oggier et al., 1998; Cameron and Pokryszko, 2005). As suggested by Emberton et al. (1996), litter collections were made at places of high micromollusc density, with a constant volume of soil litter (approximately 4 liters) being gathered from each site. For woodlands; sampling was concentrated: (1) in areas of deep litter accumulation, (2) along the base of rocks or trees, and/or (3) on soil covered bedrock ledges. For grasslands, samples consisted of: (1) small blocks (ca. $125 \mathrm{~cm}^{3}$ ) of turf; and/or (2) loose soil and leaf litter accumulations under or adjacent to shrubs, cobbles, boulders, and/or hummocks. A few Churchill (16) and Carolina coast (9) sites were sampled via field sieving of leaf litter through a $3 \mathrm{~mm}$ mesh into a $0.75 \mathrm{~mm}$ mesh. Approximately $125 \mathrm{cc}$ of processed litter was collected from each of these sites. This technique was used as it proved a more efficient way to gather individuals in habitats that lacked larger taxa.

\section{Laboratory Procedures}

Samples were slowly and completely dried in either a low-temperature soil oven (ca. $80-95^{\circ} \mathrm{C}$ ) or in full sun in a greenhouse. Dried samples were then soaked in water for 3-24 hours, and subjected to careful but vigorous water disaggregation through a standard sieve series (ASTME 3/8" (9.5 $\mathrm{mm}), \# 10(2.0 \mathrm{~mm}), \# 20(0.85)$, and \#40 (0.425 mm) mesh screens). Sieved sample fractions were dried and passed again through the same sieve series. These dry, resorted fractions were hand picked against a neutral-brown background. All shells and shell fragments were removed. All identifiable shells from each site were assigned to species (or subspecies) using the author's reference collection and the Hubricht Collection at the Field Museum of 
Natural History (FMNH), with the total number of shells per species per site being recorded. The total number of unassignable, immature individuals was also counted. Nomenclature generally follows that of Hubricht (1985), with updates and corrections by Nekola (2004).

Each site was assigned to one of five richness classes (1-4; 5-9; 10-19; 20-29; and 30-39 taxa). Complete regional fauna lists were created by combining distributional data from this study with those presented in Pilsbry (1948) and Hubricht (1985).

Approximate adult shell height and width for each encountered taxon was determined using the author's reference collection in conjunction with data presented in Pilsbry (1948). Following Emberton (1995), each taxon was placed into one of five size classes based on maximum shell dimension: micro $(<2 \mathrm{~mm})$, minute $(2-4.9 \mathrm{~mm})$, small (5-9.9 mm), medium (10-19.9 mm) and large (>20 mm). Because regional metacommunity faunas will likely harbor a greater frequency of endemic and/or low vagility taxa as compared to site faunas (Hubbell 2001), the frequency of size classes was calculated separately for geographic regions and sample sites. Additionally, the frequency of individuals within each size class was calculated for each site.

\section{Statistical Procedures}

The potential number of taxa missed within sites and regions was calculated using the Chao estimator (Chao, 1984), which considers the relative number of species in a sample represented by single individuals compared to the number of species represented by two individuals. The frequency of sites with no estimated missed taxa (Chao $<0.5$ or no singleton or doubleton species) was determined from each region. Site richness was analyzed using 1-way ANOVAs, with central tendencies being graphically represented via box plots. Log-linear modeling was used to analyze differences in richness class frequency between regions as predicted values were sparse $(<5)$ in more than onefifth of cells (Zar, 1984). Differences in size class frequency between regional faunas were analyzed using log-linear modeling. Size class frequency differences between site faunas and total individuals were tested using two-way ANOVA, with region/habitat and size class being used as independent variables. Only the significance of the region/habitat $\times$ size class interaction term was considered. Significance within each size class was documented using 1-way ANOVA. A Bonferroni correction was used to adjust the significance threshold to $\mathrm{p}=0.01$.

The relative contribution of $\alpha, \beta$ and $\gamma$ diversity to regional richness (e.g. Loreau, 2000; Veech et al., 2002) was calculated for each site. $\alpha$ diversity was set to site richness. $\beta$ diversity was calculated as the number of regional taxa not found at that site that occur only within different habitats in the region. $\gamma$ diversity was calculated as the number of regional taxa not found at that site that occur only within the same habitat type in the region. The number of regional taxa not found at that site that occur in both the same and different habitats in the region $(\beta / \gamma)$ was also determined. Comparisons between different regions were made possible via standardization by respective regional richness. One-way ANOVA was used to estimate significance for each diversity component between the sampled regions and habitats. A Bonferroni correction was used to adjust the significance threshold to $\mathrm{p}=0.0125$.

\section{RESULTS}

\section{Dataset overview}

410,667 individuals from 166 taxa were observed (Table 2). Encountered taxa per region varied from 87 in the upper Mississippi valley to 14 at Churchill. Identified individuals per region varied from 142,305 in northwestern Minnesota to 5023 in the

Table 2 Regional dataset overview: sample subjects

\begin{tabular}{|c|c|c|c|c|c|c|c|}
\hline \multirow[t]{2}{*}{ Region } & \multicolumn{5}{|c|}{ Sample Subjects } & \multicolumn{2}{|c|}{ Chao Estimator } \\
\hline & $\begin{array}{l}\text { No. taxa } \\
\text { reported }\end{array}$ & $\begin{array}{l}\text { No. taxa } \\
\text { observed }\end{array}$ & $\begin{array}{c}\text { No. } \\
\text { individuals }\end{array}$ & $\begin{array}{l}\text { No. } \\
\text { singles }\end{array}$ & $\begin{array}{l}\text { No. } \\
\text { doubles }\end{array}$ & Region & $\%$ sites $<0.5$ \\
\hline Carolina coast & 102 & 62 & 9,297 & 3 & 2 & 2.25 & $45 \%$ \\
\hline Ozarks & 98 & 54 & 12,072 & 2 & 2 & 1.00 & $100 \%$ \\
\hline New England & 85 & 67 & 19,190 & 2 & 1 & 2.00 & $66 \%$ \\
\hline Upper Mississippi & 94 & 87 & 100,901 & 2 & 2 & 1.00 & $74 \%$ \\
\hline Eastern Niagara & 101 & 79 & 24,186 & 1 & 2 & 0.25 & $58 \%$ \\
\hline Western Niagara & 93 & 83 & 78,087 & 2 & 1 & 2.00 & $56 \%$ \\
\hline Lake Superior highlands & 56 & 44 & 5,023 & 6 & 1 & 18.00 & $22 \%$ \\
\hline Northwestern Minnesota & 59 & 59 & 142,305 & 1 & 5 & 0.10 & $77 \%$ \\
\hline Southern Manitoba & 45 & 39 & 10,314 & 0 & 1 & 0.00 & $88 \%$ \\
\hline Churchill & 14 & 14 & 9,302 & 0 & 0 & 0.00 & $91 \%$ \\
\hline Total & 216 & 166 & 410,677 & 2 & 2 & 1.00 & $60 \%$ \\
\hline
\end{tabular}


Table 3 Site richness class frequency (and abundance) within each geographic region.

\begin{tabular}{lccccc}
\hline Region & \multicolumn{3}{c}{ Richness Class } & & 30+ taxa \\
\hline Carolina Coast & $\mathbf{1 - 4}$ taxa & $\mathbf{5 - 9}$ taxa & $\mathbf{1 0 - 1 9 \text { taxa }}$ & $\mathbf{2 0 - 2 9 \text { taxa }}$ & $\mathbf{3 0 +}$ \\
Ozarks & $21.1 \%(8)$ & $42.1 \%(16)$ & $26.3 \%(10)$ & $7.9 \%(3)$ & $2.6 \%(1)$ \\
New England & $0 \%(0)$ & $0 \%(0)$ & $18.2 \%(2)$ & $72.7 \%(8)$ & $9.1 \%(1)$ \\
Upper Mississippi & $6.2 \%(4)$ & $23.1 \%(15)$ & $52.3 \%(34)$ & $16.9 \%(11)$ & $1.5 \%(1)$ \\
Eastern Niagara & $0 \%(0)$ & $3.4 \%(4)$ & $42.9 \%(51)$ & $47.1 \%(56)$ & $6.7 \%(8)$ \\
Western Niagara & $2.9 \%(2)$ & $11.6 \%(8)$ & $55.1 \%(38)$ & $27.5 \%(19)$ & $2.9 \%(2)$ \\
Lake Superior highlands & $5.6 \%(12)$ & $10.7 \%(23)$ & $52.6 \%(113)$ & $30.7 \%(66)$ & $0.5 \%(1)$ \\
Northwestern Minnesota & $11.0 \%(9)$ & $39.0 \%(32)$ & $50.0 \%(41)$ & $0 \%(0)$ & $0 \%(0)$ \\
Southern Manitoba & $1.0 \%(2)$ & $7.8 \%(15)$ & $73.4 \%(141)$ & $17.7 \%(34)$ & $0 \%(0)$ \\
Churchill & $4.2 \%(1)$ & $33.3 \%(8)$ & $58.3 \%(14)$ & $4.2 \%(1)$ & $0 \%(0)$ \\
Total & $39.1 \%(9)$ & $47.8 \%(11)$ & $13.0 \%(3)$ & $0 \%(0)$ & $0 \%(0)$ \\
\hline
\end{tabular}

Lake Superior highlands. The most abundant species was Carychium exiguum with 35,312 shells. Only two taxa (Mesodon pergraptus and Polygyra pustula) were represented by single individuals. Maximum site richness of 39 taxa was observed at Williams Creek 5 in northeastern Iowa. Only a single site (the tundra summit of Mt. Mansfield, Vermont) harbored no land snails. While approximately $20 \%$ of sites harbored less than 10 taxa, over $53 \%$ contained between $10-19$, and $23 \%$ contained between 20-29 taxa. Almost $2 \%$ of sites contained 30 or more taxa (Table 3 ).

Chao estimators for regional metacommunities generally ranged from 0-2.25, with Lake Superior highlands serving as an outlier $($ Chao=18). This number is assumed to stem from random error and not inadequate sampling, as data were gathered from 82 sites spread across a $500 \mathrm{~km}$ extent, and included over 5,000 individuals. Additionally, the Chao-estimated richness for this dataset (62 taxa) greatly exceeds the total number reported from the region (56; Table 2). Site-specific Chao estimates

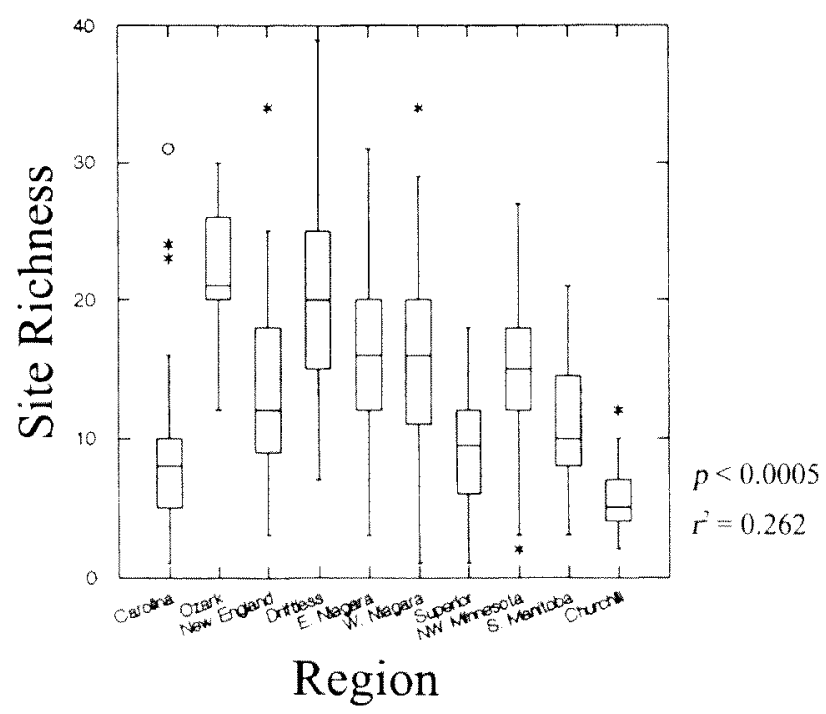

Figure 2 Box-plot diagram of variation in site richness between the ten geographic regions, $p$ and $r^{2}$ values calculated via a 1-way ANOVA. indicated that fully $60 \%$ captured all species; within regions these frequencies ranged from $22 \%$ in the Lake Superior highlands to $100 \%$ in the northern Ozarks. Additionally, Chao estimates were not calculated from 152 sites $(20 \%)$, as singleton species were present while doubletons were absent.

\section{Variation in site richness}

Site richness significantly varied $(\mathrm{p}<0.0005$; Figure 2 ), with southern regions having median values exceeding 20 while northern regions had median values of 10 or less. The five site richness classes also significantly varied $(p<0.000005)$ between geographic regions (Table 3 ). Churchill and coastal Carolina were similar $(p=0.15)$, being dominated by sites harboring less than 10 taxa. The Lake Superior highlands and southern Manitoba were similar $(\mathrm{p}=0.347)$, having approximately equal numbers of sites possessing 1-9 or 10-19 taxa. Northwestern Minnesota was statistically distinct ( $p=0.00008$ vs. New England, eastern Niagara and western Niagara), having less than $10 \%$ of sites harboring less than 10 taxa, $73 \%$ of sites harboring $10-19$, and almost 18\% harboring 20-29 taxa. The New England, eastern Niagara and western Niagara regions were similar $(p=0.128)$, having approximately half of sites harboring 10-19 taxa, and $17-31 \%$ of sites $20-29$ taxa. From $0.5-3 \%$ of sites in these regions supported 30 or more taxa. The northern Ozarks and upper Mississippi valley regions were also similar $(p=0.194)$, having essentially no sites harboring fewer than 10 taxa, and approximately $50 \%$ harboring more than 20 . Seven to nine percent of sites in these regions harbored 30 or more taxa.

Significant variation $(\mathrm{p}<0.0005)$ was also noted between the five major habitat groups (Figure 3), with bedrock outcrops having a median score of 18 , upland and lowland forest sites of 13, lowland grasslands of 12, and upland grasslands of 11 . Additionally, base-rich sites were found to harbor almost twice as many species, on average, as oligotrophic sites $(p<0.0005$; Figure 4). Significant 


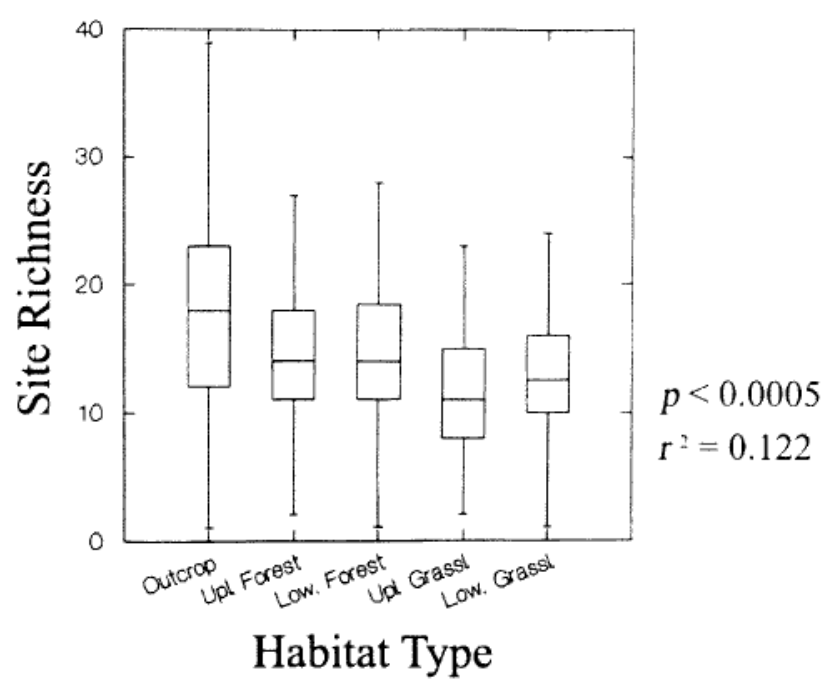

Figure 3 Box-plot diagram of variation in site richness between the five major habitat types. $p$ and $r^{2}$ values calculated via a 1-way ANOVA.

depression of richness in oligotrophic sites was also noted within all five habitat groups (rock outcrop, $\mathrm{p}<0.0005$; upland forest, $\mathrm{p}<0.0005$; lowland forest, $\mathrm{p}<0.0005$, upland grassland, $\mathrm{p}=0.006$; lowland grassland, $p=0.010)$, and within most of the geographic regions (e.g. Carolina coast, $\mathrm{p}<0.0005$;

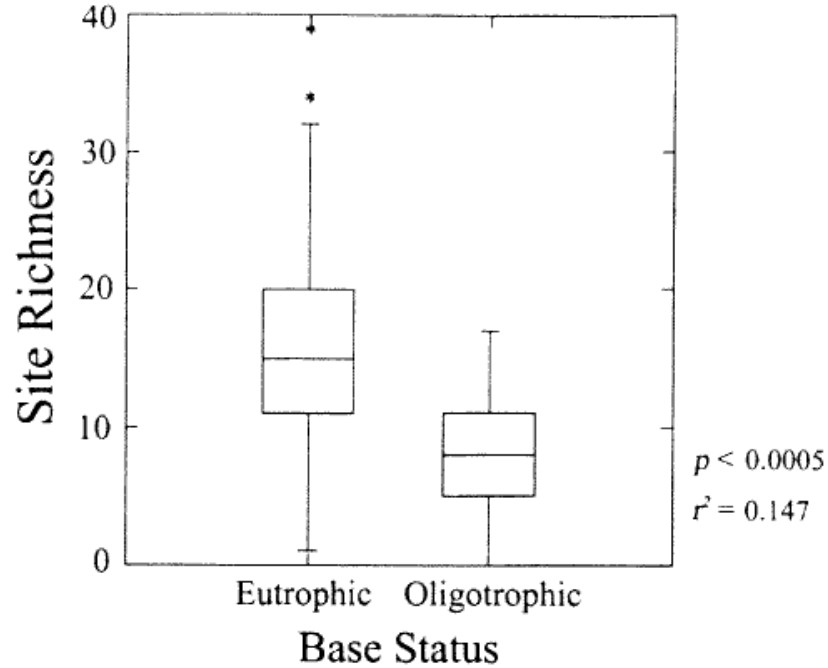

Figure 4 Box-plot diagram of variation in site richness between base-rich and oligotrophic habitats. $p$ and $r^{2}$ values calculated via a 1-way ANOVA.

New England, $\mathrm{p}<0.0005$; northwestern Minnesota, $p<0.0005$; western Niagara escarpment, $p=0.005$ ). However, no significant differences were noted between these habitat types in the Lake Superior highlands $(p=0.747)$ and southern Manitoba $(\mathrm{p}=0.122)$.

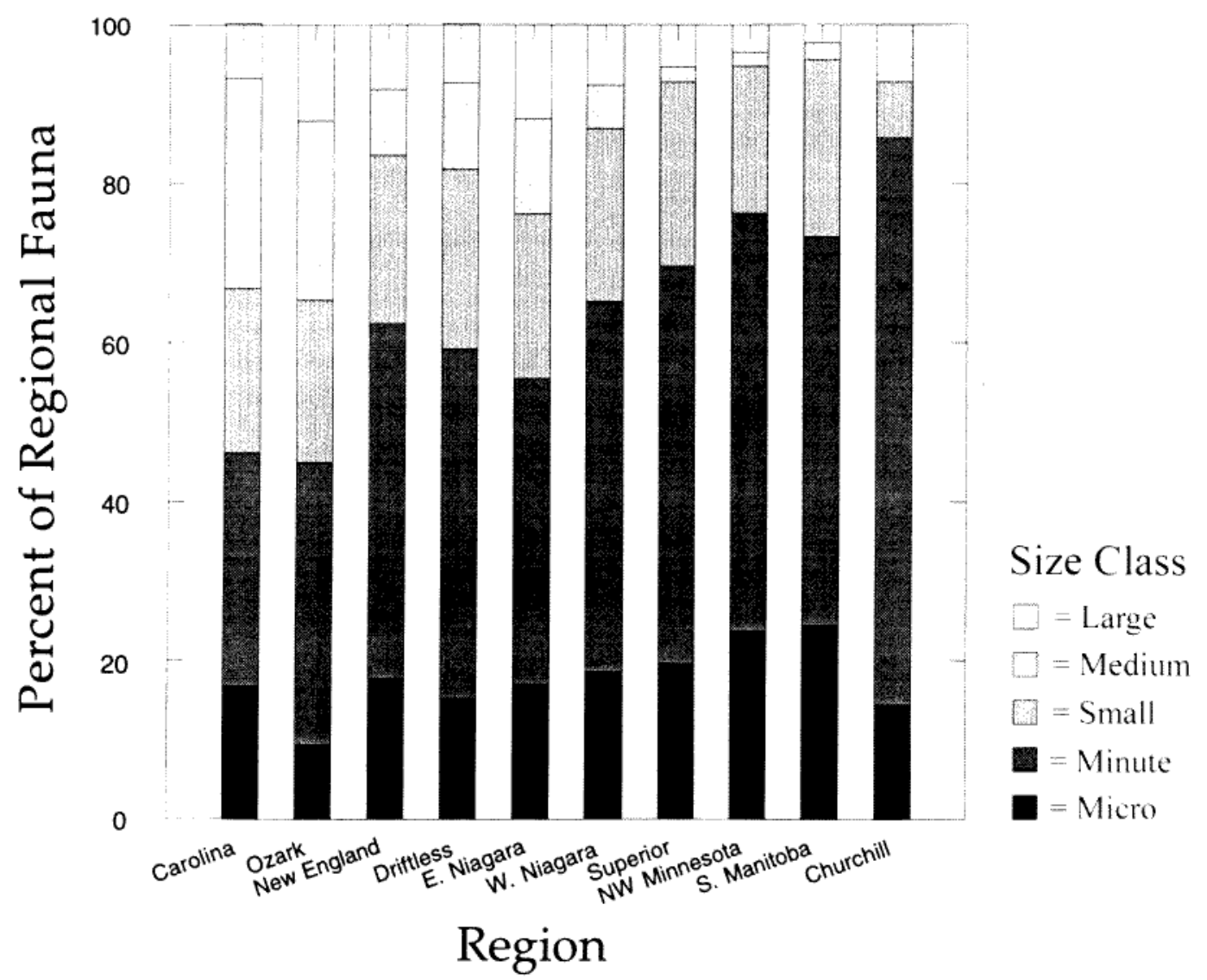

Figure 5 Size class distribution between the ten regional faunas. Micro species have a maximum shell dimension of $<2 \mathrm{~mm}$; minute 2-4.9 mm; small 5-9.9 mm; medium 10-19.9 mm, and large 20+ $\mathrm{mm}$. 


\section{Variation of shell size distribution}

Shell size distribution varied significantly $(p=0.00004)$ among the ten regional faunas (Figure $5)$. The Carolina coast and northern Ozarks faunas are similar $(\mathrm{p}=0.32243)$ and represented by roughly similar percentages of all five size classes. The New England, upper Mississippi valley, New England, eastern Niagara, western Niagara, Lake Superior highland, northwestern Minnesota, and southern Manitoba regions are all similar $(p=0.39993)$, with approximately $20 \%$ of taxa being micro, $40-50 \%$ being minute, and $20 \%$ being of small size. Only 5
$20 \%$ of taxa were of medium or large size. The Churchill fauna is statistically distinct $(\mathrm{p}=0.00005)$ by having $85 \%$ of taxa being of micro or minute size. The proportion of regional faunas represented by micro or minute taxa increased steadily from the south $(45 \%)$ to the north $(85.7 \%)$, while the number of medium and large taxa fell ( $35 \%$ to $4 \%)$.

The size distribution of site faunas varied significantly between regions $(p<0.00005$; Figure 6) with each size class demonstrating significant $(\mathrm{p}<0.00005)$ differences. The proportion of small taxa tended to increase towards the north $(14 \%$ to
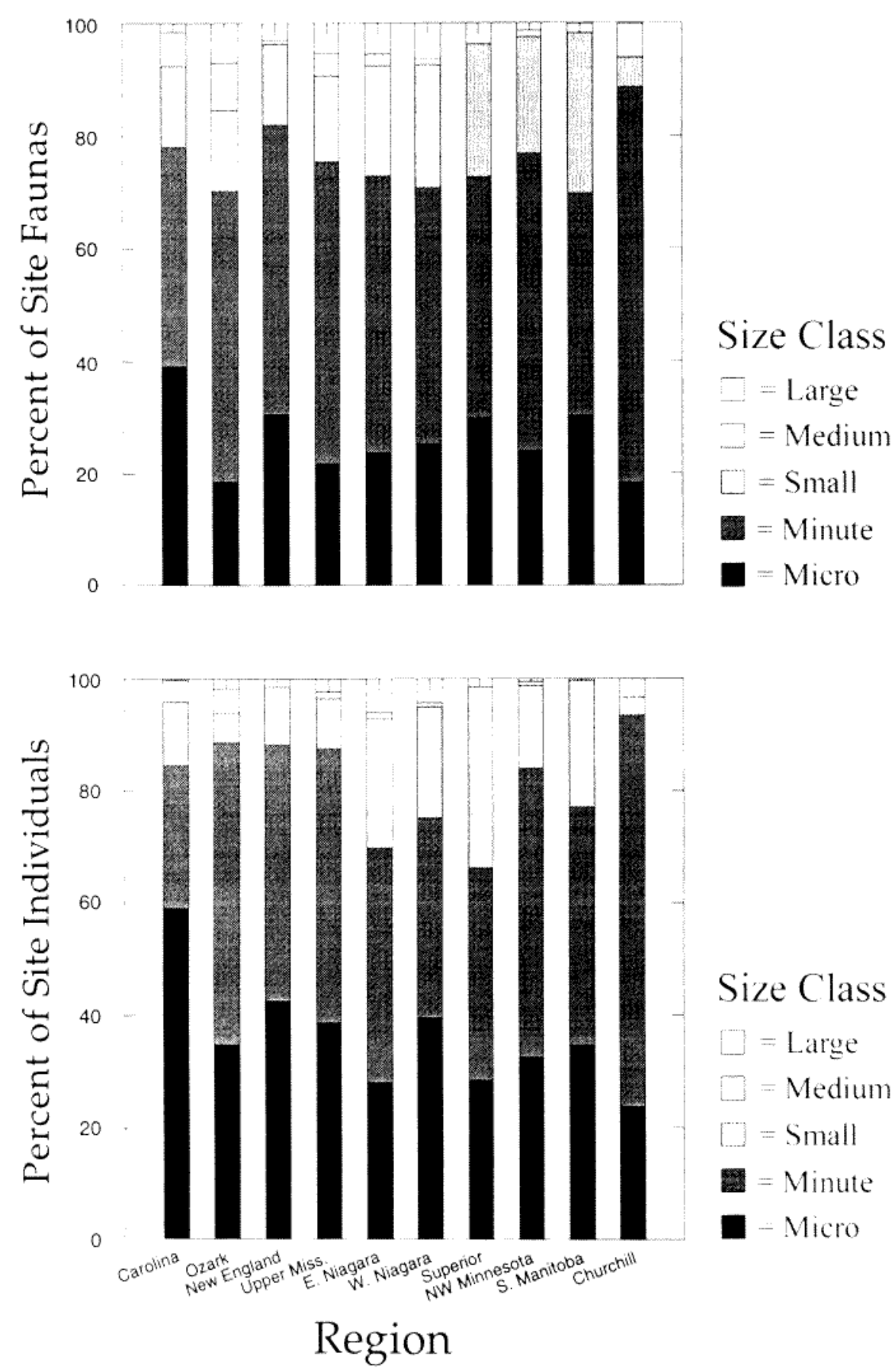

Figure 6 Average size class distributions for site faunas and site individuals across the ten geographic regions. Micro species have a maximum shell dimension of $<2 \mathrm{~mm}$; minute $2-4.9 \mathrm{~mm}$; small 5-9.9 mm; medium 10-19.9 $\mathrm{mm}$, and large $20+\mathrm{mm}$. 
$29 \%$ ), while the number of medium and large taxa fell $(15 \%$ to $0 \%)$. Ozark and Churchill sites demonstrated the lowest average frequency of micro taxa $(<20 \%)$, while the Carolina coast, New England, Lake Superior highlands, and southern Manitoba had the highest (30-39\%). Carolina coast and southern Manitoba sites demonstrated the lowest average frequency of minute taxa $(<40 \%)$, with Churchill having the highest $(70 \%)$. Churchill sites demonstrated the lowest average frequency of small taxa $(5 \%)$, with southern Manitoba having the highest $(29 \%)$. Lake Superior highlands and southern Manitoba sites demonstrated the lowest average frequency of medium taxa $(0 \%)$, with the Ozarks having the highest $(8 \%)$. Churchill sites demonstrated the lowest average frequency of large taxa $(0 \%)$ with the Ozarks again having the highest $(7 \%)$.

The size distribution of individuals also varied significantly between regions ( $\mathrm{p}<0.00005$; Figure 6 ) with each size class demonstrating significant $(p<0.00005)$ differences. The proportion of micro individuals tended to decrease towards the north $(59 \%$ to $23 \%)$, while the number of minute
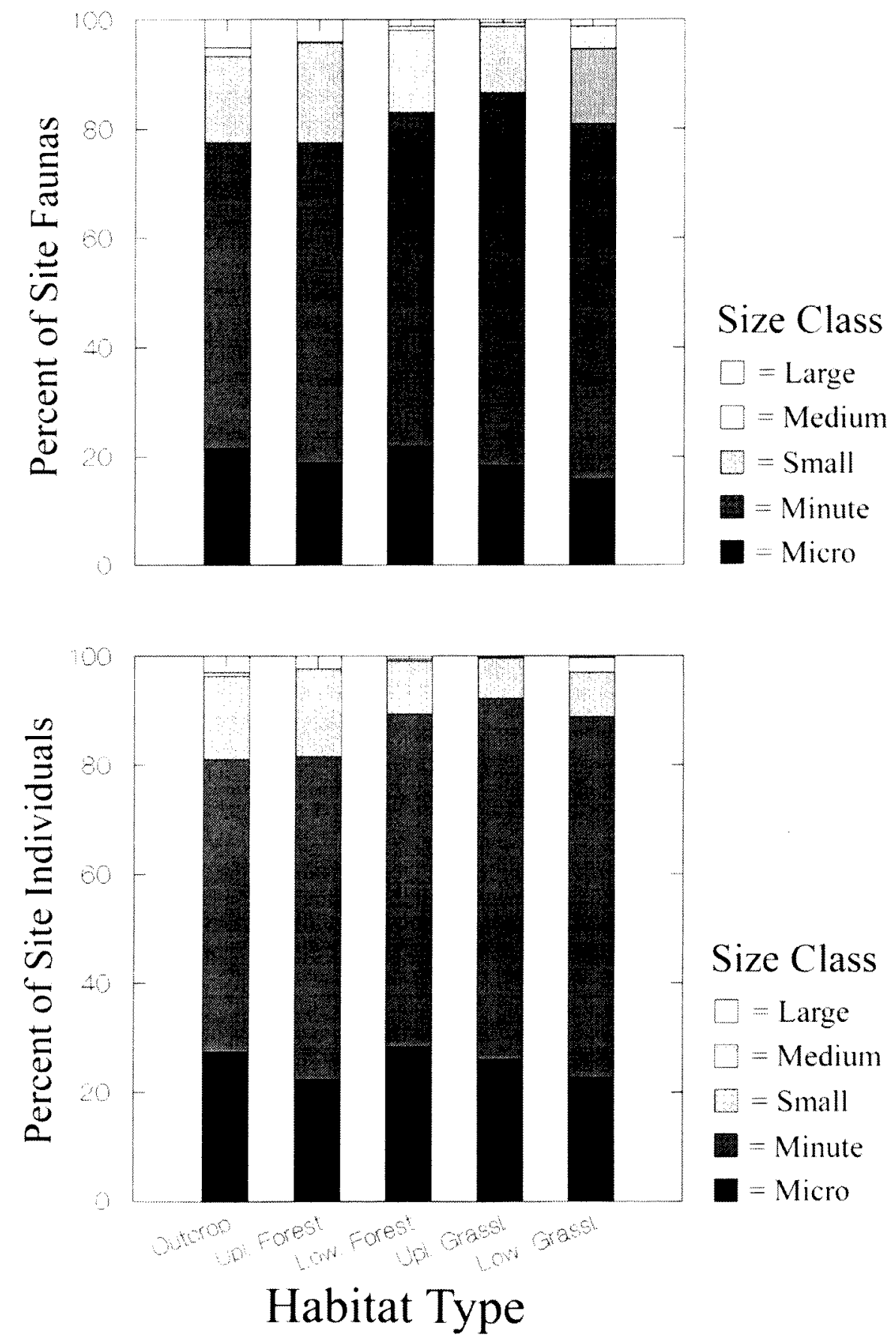

Figure 7 Average size class distributions for site faunas and site individuals across the five habitat types. Micro species have a maximum shell dimension of $<2 \mathrm{~mm}$; minute $2-4.9 \mathrm{~mm}$; small $5-9.9 \mathrm{~mm}$; medium $10-19.9 \mathrm{~mm}$, and large $20+\mathrm{mm}$. 
individuals increased $(26 \%$ to $70 \%)$. The proportion of small, medium and large individuals tended to be greatest in the mid-latitudes (34-24\%). Churchill sites demonstrated the lowest average frequency of micro individuals $(24 \%)$, while the Carolina coast had the highest $(59 \%)$. Carolina coast sites demonstrated the lowest average frequency of minute individuals $(26 \%)$, with Churchill having the highest $(70 \%)$. Churchill sites demonstrated the lowest average frequency of small individuals (3\%), with the Lake Superior highlands having the highest $(32 \%)$. Lake Superior highlands and southern Manitoba sites demonstrated the lowest average frequency of medium individuals $(0 \%)$, with the Ozarks having the highest $(4 \%)$. Churchill sites demonstrated the lowest average frequency of large taxa $(0 \%)$ with the eastern Niagara having the highest $(6 \%)$.

The size distribution of site faunas varied significantly between habitat types $(p<0.00005$; Figure 7) with each size class demonstrating significant $(p<0.00005)$ differences. The proportion of medium and large taxa tended to be much less in upland grasslands and lowland forests $(<2 \%)$ as compared to the remaining habitats $(4 \%-7 \%)$. Lowland grassland sites demonstrated the lowest average frequency of micro taxa $(16 \%)$, while outcrops and lowland forests had the highest $(>21 \%)$. Outcrop sites demonstrated the lowest average frequency of minute taxa $(56 \%)$, with upland grasslands having the highest $(68 \%)$.
Upland grassland sites demonstrated the lowest average frequency of small taxa $(12 \%)$, with upland forests having the highest $(18 \%)$. Upland forest sites demonstrated the lowest average frequency of medium taxa $(0.7 \%)$, with lowland grasslands having the highest $(4 \%)$. Upland grassland sites demonstrated the lowest average frequency of large taxa $(0.4 \%)$ with outcrops having the highest $(5 \%)$.

The size distribution of individuals also varied significantly between habitat types $(p<0.00005$; Figure 7) with each size class demonstrating significant $(\mathrm{p}<0.00005)$ differences. The proportion of small and large individuals tended to be greatest in outcrop and upland forest habitats $(>15 \%$, and $>2 \%$, respectively). Upland forest and lowland grassland sites demonstrated the lowest average frequency of micro individuals $(<23 \%)$, while lowland forests had the highest $(28 \%)$. Outcrop sites demonstrated the lowest average frequency of minute individuals $(54 \%)$, with both grassland habitats having the highest $(66 \%)$. Upland grassland sites demonstrated the lowest average frequency of small individuals $(7 \%)$, with upland forests having the highest (16\%). Lowland forest sites demonstrated the lowest average frequency of medium individuals $(0.08 \%)$, with lowland grasslands having the highest (3\%). Upland grassland sites demonstrated the lowest average frequency of large individuals $(0.08 \%)$ with outcrops having the highest $(3 \%)$.

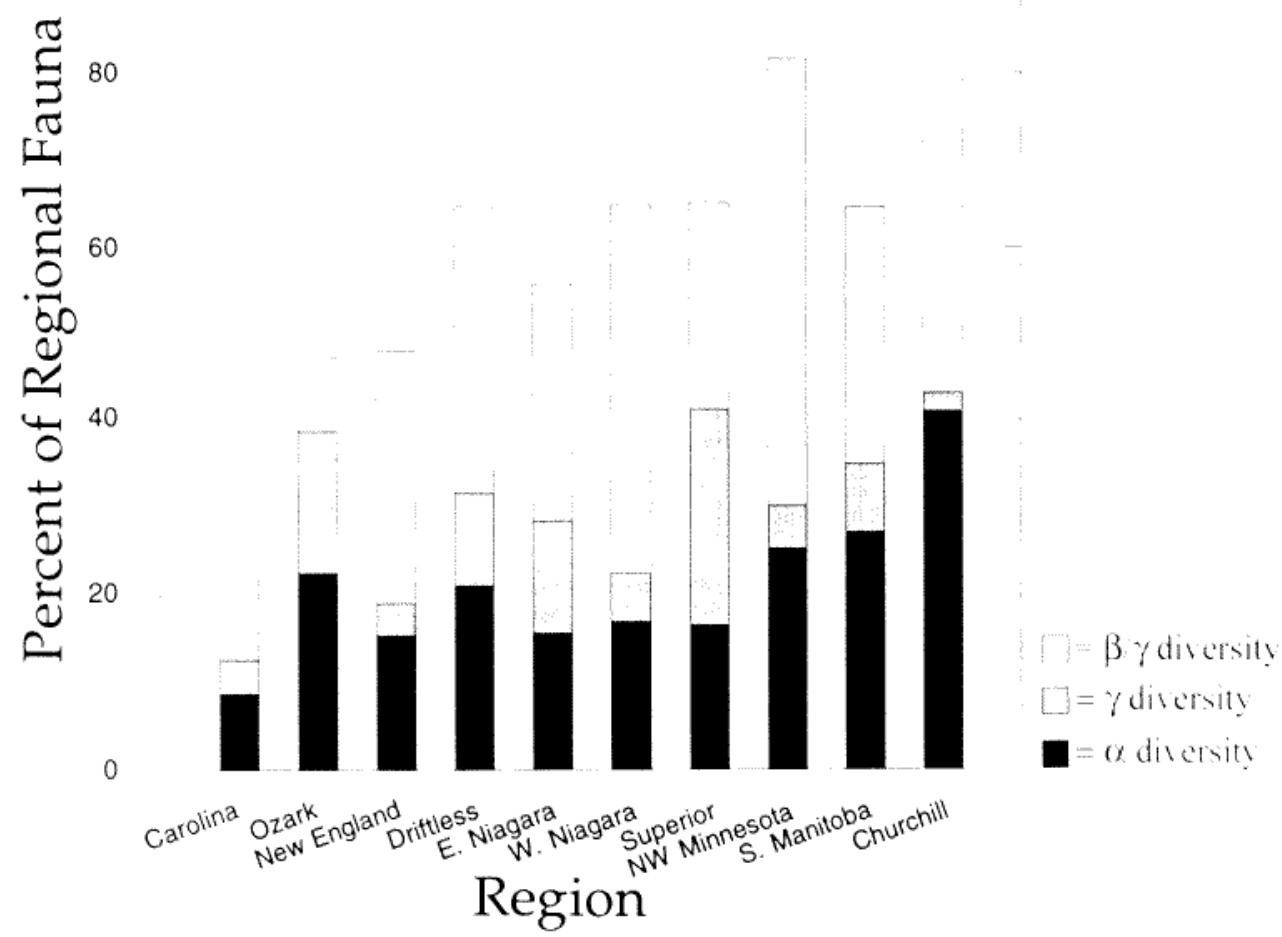

Figure 8 Relative average contribution of $\alpha, \gamma$, and $\beta / \gamma$ diversity to the regional species pool within all geographic regions. 
Variation in the relative contribution of $\alpha, \beta$, and $\gamma$ diversity

Significant variation $(\mathrm{p}<0.0005)$ was noted in the contribution of $\alpha, \beta, \gamma$, and $\beta / \gamma$ diversity to regional richness between the geographic regions (Figure 8). Geographic region explained $35 \%$ of observed variation in the contribution of $\alpha$ diversity, $19 \%$ of $\beta, 50 \%$ of $\gamma$, and $65 \%$ of $\beta / \gamma$. The proportion of the regional fauna captured by an average site positively varied with latitude, increasing from $7 \%$ on the Carolina coast to $>40 \%$ in Churchill. Broadlydefined $\gamma$ diversity $(\gamma+\beta / \gamma$ or all other species found in other sites of the same habitat type within the region) also tended to increase with latitude, representing approximately $20 \%$ of the regional fauna in the Ozarks and Carolina coast to more than $50 \%$ of the regional fauna in northwestern Minnesota, the Lake Superior highlands, and western Niagara. The contribution of $\beta$ diversity to regional richness decreased with latitude from approximately $70 \%$ on the Carolina coast to $20 \%$ in northwest Minnesota and Churchill.

The contribution of $\alpha$ to regional diversity (ca. $20 \%)$ did not significantly vary $(\mathrm{p}=0.054)$ between habitat types (Figure 9). However, significant variation $(\mathrm{p}<0.0005)$ was noted in the contribution of $\beta, \gamma$, and $\beta / \gamma$ diversity. Habitat type explained $44 \%$ of observed variation in the contribution of $\beta$ diversity to regional richness, $66 \%$ of $\gamma$, and $15 \%$ of $\beta / \gamma$. Levels of pure $\gamma$ diversity (the number of taxa found only in other sites of the same habitat type) in rock outcrops was $18 \%$, almost triple that for all other habitats. The contribution of $\beta$ diversity to regional richness was greatest in grassland $(>40 \%)$ and least in outcrops and upland forests (approximately $25 \%$ ).

\section{DISCUSSION}

\section{Richness Patterns}

Eastern North American land snail communities are frequently marked by high levels of syntopic species richness at the 0.1 ha scale. Only on the Carolina coast and at Churchill did a majority of sites support fewer than 10 taxa. Of the remaining regions only the Lake Superior highlands and southern Manitoba demonstrated a significant lack of sites supporting 20 or more taxa. For the upper Mississippi valley and Ozarks, the majority of sites reached this richness level, with essentially no sites supporting fewer than 10 taxa. Sites supporting 30 or more taxa, which approach the richest Australia, western Europe, tropical Africa, and New Zealand sites (Schmid, 1966; Tattersfield, 1996; Stanisic, 1997; de Winter and Gittenberger, 1998; Barker and

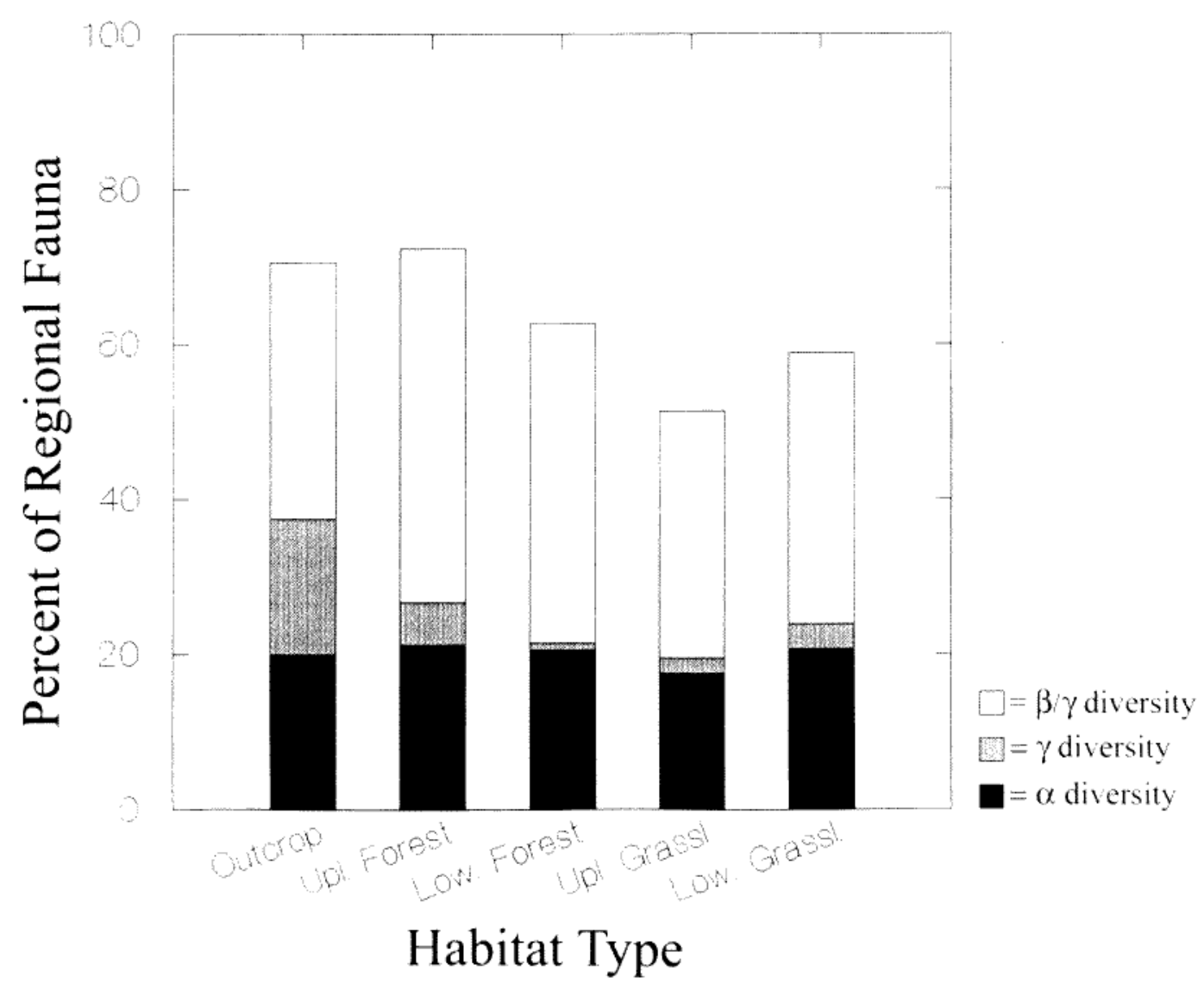

Figure 9 Relative average contribution of $\alpha, \gamma$, and $\beta / \gamma$ diversity to the regional species pool within all habitat types. 
Mayhill, 1999; Cameron, 2004, Stanisic and Ponder, 2004), were recorded from the six most southern regions.

The assertion by Solem and Climo (1985) that continental land snail community richness rarely exceeds 12 can thus be easily disproved, as over $52 \%$ of all sites (438), and up to $91 \%$ within a given region exceeded this threshold. Even though the Churchill region lacked such sites, 12 out of 14 regional taxa were observed co-occurring on single sites. Additionally, 9.7\% (81) sites (from all regions but the Lake Superior highlands, southern Manitoba, and Churchill) equaled or exceeded 24 co-occurring taxa, a benchmark used by Tattersfield (1996) to identify sites of global molluscan conservation importance.

As a 5-fold decrease in site richness was noted from the south (ca. 25) to the north (ca. 5), the eastern North American land snail fauna exhibits a latitudinal richness gradient similar to those seen for birds and mammals in the same landscape (Brown and Gibson, 1983). This reduction in richness, however, is likely more rapid at some latitudes than others (Nekola, 1999).

Soil base-status is an important confounder, with oligotrophic sites having much lower richness as compared to base-rich sites. Significant differences remained when comparisons were limited to the same habitat type, and were also present within most of the geographic regions. It is thus not surprising that the Carolina coast, which contains the highest proportion of oligotrophic habitats (bay and pine forest, pine-wiregrass savanna, pocosin peatlands), had median site richness levels comparable to that of tundra. Calcareous woodlands in this landscape, however, were as rich as those in the Ozarks. Other landscapes with a high proportion of oligotrophic habitats (e.g. New England, Lake Superior highlands) had depressed site richness levels as compared to other regions of similar latitude with a higher proportion of nutrient-rich sites (e.g. upper Mississippi valley, northwestern Minnesota). The decrease of landsnail richness on oligotrophic sites has been previously demonstrated not only along the Niagara escarpment in eastern North America (Nekola, 1999), but also in western and central Europe (Agócsy, 1968; Bishop, 1976; Waldén, 1981; Gärdenfors, 1992; Outeiro et al., 1993). Faunas of oligotrophic sites also often demonstrate less evenness in the distribution of their species abundances (Valovirta, 1968; Cameron and Pokryszko, 2005).

The documentation of rock outcrops as harboring the richest site faunas, and upland grasslands the least has been previously shown within the more limited extent of the western Great Lakes (Nekola, 1999, 2003). Eastern North America can thus be added to the growing list of landscapes (Australia:
Stanisic, 1997; Borneo: Schilthuizen, 2004; Germany: Schmid, 1966; Scotland: Cameron and Greenwood, 1992; Sweden: Waldén, 1981) in which calcareous bedrock outcrops serve as the most important reservoirs for land snail biodiversity.

\section{Size Distribution Patterns}

The eastern North American fauna is characterized by minute and micro taxa, particularly at the site scale, where in most regions almost $80 \%$ of species and over $80 \%$ of individuals are of this size. The contribution of medium and large taxa to site faunas and individuals, however, rarely exceeds $10 \%$. This size class distribution is similar to that reported from tropical Africa (de Winter and Gittenberger, 1998) and New Zealand (Barker and Mayhill, 1999), and may help explain why the North American fauna was long considered depauperate (Solem, 1984): unlike European faunas (Kerney and Cameron, 1979), few species and individuals within sites are large enough to be easily observed in the field. Eastern North American land snail faunas thus require leaf litter examination for accurate characterization of community and diversity patterns.

Southern regional species pools also include a wider variety of size classes as compared to northern areas, with the proportion of minute (and to a lesser extent micro) species increasing with latitude, while the proportion of both medium and large taxa decreased. Shell size distribution also varied at the site scale, with the proportion of micro individuals falling almost $2 / 3$ with increasing latitude $(60 \%$ to $20 \%)$ while minute taxa demonstrated the inverse pattern $(25 \%$ to $70 \%)$. Medium and large taxa never constituted more than $16 \%$ of site faunas and $7 \%$ of site individuals, with these proportions tending to be larger towards the south.

These data suggest a greater variety of niches or guilds are present in the south, as has been shown for birds (Terborgh, 1992). Additionally, as micro and minute taxa are more frequent in site vs. regional faunas and medium and large taxa are less, smaller taxa appear to either possess broader niches and/or more completely saturate potential habitats within a landscape as compared to their larger counterparts. The greater apparent number of niches/guilds in outcrop sites is likely related to high levels of small-scale environmental heterogeneity (Larson et al., 2000).

\section{Relative Contributions of $\alpha, \beta$, and $\gamma$ diversity}

A significant latitudinal gradient was present, with $\alpha$ diversity ranging from $9 \%$ of regional richness on the Carolina coast to $41 \%$ in Churchill. Broadly construed $\gamma$ diversity also tended to increase with latitude from approximately $20 \%$ of regional richness on the Carolina coast to $38 \%$ in 
Churchill and 56\% in northwestern Minnesota. As a result, the contribution of narrowly defined $\beta$ diversity fell from approximately $70 \%$ of regional richness on the Carolina coast to approximately $20 \%$ in northwestern Minnesota and Churchill. These data suggest that northern communities either consist of species with wider ecological niches or are more environmentally similar as compared to those in the south. The increased relative contribution of site richness to regional richness in conjunction with decreased compositional turnover between habitats towards the north agrees with analyses from other taxa groups (Ricklefs, 1990; Terborgh, 1992).

However, the decrease in $\gamma$ diversity contribution towards the south was not expected. Generally, $\gamma$ diversity rates tend to decrease towards the poles (Nekola and White, 1999; Pokryszko and Cameron, this volume). The observed pattern may be related to species niche breadth. Large niche breadths in the north would allow a greater percentage of the regional fauna to colonize other examples of a given habitat type, causing $\gamma$ diversity rates (as defined for these analyses) to increase. However, narrower niche breadths in the south would cause each habitat type to harbor a smaller percentage of the regional fauna, decreasing the fraction of the remaining species pool that would be encountered by searching other examples of the same habitat. This explanation would also predict a greater amount of pure $\gamma$ diversity in south, as more species become habitat specialists. However, as this pattern was not observed, the ultimate causes remain ambiguous.

Significant differences between habitats were also observed in the relative contribution of $\beta$ and $\gamma$ diversity to regional richness, with the latter being highest in outcrop and upland forest and lowest in grassland habitats. The importance of $\gamma$ diversity for outcrop sites may be related to their isolated nature in landscapes (Larson et al., 2000), which will increase their rates of geographic compositional turnover (Nekola and White, 1999).

\section{ACKNOWLEDGEMENTS}

Funding was provided by the Door County Office of the Wisconsin Chapter of The Nature Conservancy, a Louis Almon grant (administered by the Wisconsin Academy of Sciences, Arts, and Letters), three Cofrin Arboretum grants (administered by the Cofrin Arboretum Committee at the University of Wisconsin - Green Bay), the U.S. Fish and Wildlife Service, and the Small Grants Program of the Michigan Department of Natural Resources. Funding for the survey of Minnesota sites was received from the Minnesota Nongame Wildlife Tax Checkoff and Minnesota State Park Nature Store Sales through the Minnesota
Department of Natural Resources Natural Heritage and Nongame Research Program. Helpful comments on earlier versions of this manuscript were provided by Robert Cameron and Beata Pokryszko.

\section{REFERENCES}

Agócsy, P. (1968). Data on quantitative conditions in the mollusk faunas of two different substrates in central Hungary. Acta Zoologica Academiae Scientarium Hungaricae 14: 1-6.

Bank, R.A., Falkner, G., Gittenberger, G., Hausdorf, B., von Proschwitz, T. and Ripken, T.E.J. (1998). Biodiversity of the western Palaerctic region as exemplified by continental Mollusca. World Congress of Malacology, Washington, D.C. Abstract \#25. Smithsonian Institution, Washington, D.C.

Barbour, M.G. and Billings, W.D. (1988). North American Terrestrial Vegetation. Cambridge University Press, New York.

Barker, G.M. (2001). Gastropods on land: phylogeny, diversity, and adaptive morphology. In G.M. Barker (ed.), The Biology of Terrestrial Molluscs. 1-146. CABI Publishing, Wallingford, New Zealand.

Barker, G.M. (2005). The character of the New Zealand land snail fauna and communities: some evolutionary and ecological perspectives. Records of the Western Australian Museum Supplement 68: 53102.

Barker, G.M. and Mayhill, P.C. (1999). Patterns of diversity and habitat relationships in terrestrial mollusc communities of the Pukeamaru Ecological District, northeastern New Zealand. Journal of Biogeography 26: 215-238.

Behan-Pelletier, V. and Newton, G. (1999). Linking soil biodiversity and ecosystem function - the taxonomic dilemma. Bioscience 49: 149-153.

Bishop, M.J. (1976). Woodland mollusca around Nettlecombe, Somerset. Field Studies 4: 457-464.

Brown, J.H. and Gibson, A.C. (1983). Biogeography. C.V. Mosby Company, St. Louis.

Burch, J.B. and Pearce, T.A. (1990). Terrestrial Gastropoda. In D.L. Dindal (ed.), Soil Biology Guide. 201-309. John Wiley \& Sons, New York.

Cameron, R.A.D. (2004). From continents to quadrats: species/area relationships in land mollusc faunas. Journal of Conchology, Special Publication 3: 39-54.

Cameron, R.A.D. and Greenwood, J.J.D. (1992). Some montane and forest molluscan fauna from eastern Scotland: effects of altitude, disturbance, and isolation. In Proceedings of the Tenth International Malacological Congress, Tuibingen, 1989 437-442.

Cameron, R.A.D. and Pokryszko, B.M. (2005). Estimating the species richness and composition of land mollusc communities. Journal of Conchology 38: 529-547.

Chao, A. (1984). Non-parametric estimation of the number of classes in a population. Scandinavian Journal of Statistics. 11: 265-270.

Cody, M.L. (1986). Diversity, rarity, and conservation in Mediterranean-climate regions. In M.E. Soulé (ed.), 
Conservation Biology. 122-152. Sinauer Associates, Sunderland, Massachusetts.

Emberton, K.C. (1995). Land-snail community morphologies of the highest-diversity sites of Madagascar, North America, and New Zealand, with recommended alternatives to height-diameter plots. Malacologia 36: 43-66.

Emberton, K.C., Pearce, T.A. and Randalana, R. (1996). Quantitatively sampling land-snail species richness in Madagascan rainforests. Malacologia 38: 203-212.

Emberton, K.C., Pearce, T.A., Kasigwa, P.F., Tattersfield, P. and Habibu, Z. (1997). High diversity and regional endemism in terrestrial gastropods of eastern Tanzania. Biodiversity and Conservation 6: 1123-1136.

Gärdenfors, U. (1992). Effects of artificial liming on terrestrial gastropod populations. Journal of Applied Ecology 29: 50-54.

Hubbell, S.P. (2001). The Unified Neutral Theory of Biodiversity and Biogeography. Princeton University Press, Princeton, New Jersey.

Hubricht, L. (1985). The distributions of the native land mollusks of the eastern United States. Fieldiana n.s. 24: 1-191.

Kerney, M.P. and Cameron, R.A.D. (1979). Field Guide to the Land Snails of the British Isles and Northwestern Europe. Collins Press, London.

Larson, D.W., Mattes, U. and Kelly, P.E. (2000). Cliff ecology. Cambridge University Press, New York.

Loreau, M. (2000). Are communities saturated? On the relationship between $\alpha, \beta$, and $\gamma$ diversity. Ecology Letters 3: 73-76.

Oggier, P., Zschokke, S. and Baur, B. (1998). A comparison of three methods for assessing the gastropod community in dry grasslands. Pedobiologia 42: $348-357$

Outeiro, A., Agüera, D. and Parejo, C. (1993). Use of ecological profiles and canonical correspondence analysis in a study of the relationship of terrestrial gastropods and environmental factors. Journal of Conchology 34: 365-375.

Nekola, J.C. (1999). Terrestrial gastropod richness of carbonate cliff and associated habitats in the Great Lakes region of North America. Malacologia 41: 231252.

Nekola, J.C. (2003). Large-scale terrestrial gastropod community composition patterns in the Great Lakes region of North America. Diversity and Distribution 9: 55-71.

Nekola, J.C. (2004). Terrestrial gastropod fauna of northeastern Wisconsin and the southern Upper Peninsula of Michigan. American Malacological Bulletin 18: $21-44$.

Nekola, J.C. and White, P.S. (1999). Distance decay of similarity in biogeography and ecology. Journal of Biogeography 26: 867-878.

Pilsbry, H.A. (1948). Land Mollusca of North America (North of Mexico). Academy of Natural Sciences of Philadelphia, Monograph \#3.
Pokryszko, B.M. and Cameron, R.A.D. (2005). Geographical variation in the composition and richness of forest snail faunas in northern Europe. Records of the Western Australian Museum Supplement 68: 115-132.

Ricklefs, R.E. (1990). Ecology. W.H. Freeman \& Co., New York.

Schilthuizen, M. (2004). Land snail conservation in Borneo: limestone outcrops act as arks. Journal of Conchology, Special Publication 3: 149-154.

Schmid, G. (1966). Die mollusken des Spitzbergs. Der Spitzberg bei Tübingen, Natur und Landschaftsschutzgebiete, Baden-Württemberg 3: 596-701.

Shmida, A. and Ellner, S. (1984). Coexistence of plant species with similar niches. Vegetatio 58: 29-55.

Solem, A., (1984). A world model of land snail diversity and abundance. In A. Solem \& A.C. Van Bruggen (eds), World-wide Snails: Biogeographical Studies on Nonmarine Mollusca. 2-66. E.J. Brill/W. Backhuys, Leiden.

Solem, A. and Climo, F.M. (1985). Structure and habitat correlations of sympatric New Zealand land snail species. Malacologia 26: 1-30.

Stanisic, J. (1997). An area of exceptional land snail diversity: the Macleay Valley, north-eastern New South Wales. Memoirs of the Museum of Victoria 56: $441-448$.

Stanisic, J. and Ponder, W.F. (2004). Forest snails in Eastern Australia - one aspect of the other $99 \%$. In D. Lunney (ed.), Conservation of Australia's Forest Fauna (2nd Edition). 127-149. Royal Zoological Society of New South Wales, Mosman, NSW.

Tattersfield, P. (1996). Local patterns of terrestrial gastropod diversity in a Kenyan rain forest. Malacologia 38: 161-180.

Terborgh, J. (1992). Diversity and the Tropical Rain Forest. Scientific American Library, W.H. Freeman and Company, New York.

Valovirta, I. (1968). Land molluscs in relation to acidity on hyperite hills in Central Finland. Annales Zoologici Fennici 5: 245-253.

Veech, J.A., Summerville, K.S., Crist, T.O. and Gering, J.C. (2002). The additive partitioning of species diversity: recent revival of an old idea. Oikos 99: 3-9.

Waldén, H.W. (1981) Communities and diversity of land molluscs in Scandinavian woodlands. 1. High diversity communities in taluses and boulder slopes in SW Sweden. Journal of Conchology 30: 351-372.

Whittaker, R.H. (1975). Communities and Ecosystems. MacMillan Publishing Company, New York.

Winter, A.J. de and Gittenberger, E. (1998). The terrestrial gastropod fauna of a square kilometer patch of rainforest in southwestern Cameroon: high species richness, low abundance, and seasonal fluctuations. Malacologia 40: 231-250.

Zar, J.H. (1984) Biostatistical Analysis. Prentice-Hall, Inc., Englewood Cliffs, New Jersey. 